\title{
Total diz artroplastisinde insizyon kapatılırken diz pozisyonunun, postoperatif ağrı ve fonksiyona etkisi
}

\section{The effect of wound closure position in total knee arthroplasty on postoperative pain and function}

\author{
Çağdaş PAMUK* \\ Medical Park Silivri Hastanesi, Ortopedi ve Travmatoloji Bölümü, İstanbul/TÜRKIYE
}

\section{Öz}

Amaç: Literatürde total diz artroplastisi (TDA) sırasında inzisyonun hangi pozisyonda kapatılması gerektiği konusunda fikir birliği yoktur. İnsizyon bölgesindeki gerginlik, hematom oluşması aynı zamanda ekstensör mekanizmanın uyumsuz kapatılmasının erken dönemde kötü fonksiyonel sonuçlar doğurabileceği bildirilmiştir. Bu çalışmada TDA sırasında dizin tam fleksiyon pozisyonunda insizyonun kapatılması ile tam ekstansiyon pozisyonda kapatılmasının, postoperatif ağrı ve fonksiyona olan etkisini araştırmayı amaçladık.

Gereç ve Yöntemler:lleri derece gonartroz nedeniyle TDA operasyonu planlanan 61 hasta çalışmaya dahil edildi. TDA sırasından insizyonu diz maksimum fleksiyon pozisyonundayken sütüre edilen 30 hasta Grup 1 olarak, tam ekstansiyon pozisyonunda sütüre edilen 31 hasta Grup 2 olarak belirlendi. Gruplar arasında (1) hastaların demografik özellikleri (yaş, kilo, beden kitle indeksi (BKi)) (2) preop, postop 1. hafta, postop 2. hafta eklem hareket açıklığı değerleri ve ağıı skorları karşılaştıııldı.

Bulgular:Gruplar arasında ağrı değerleri açısından preoperatif dönemde anlamlı bir fark yoktur. Postop 1. haftada eklem hareket açıkığı ve ağrı skorları Grup 1'de anlamlı oranda düşüktür ( $(<0,001)$. 6. hafta incelendiğinde gruplar arasında anlamlı bir fark görülmemektedir.

Sonuç: TDA da insizyonun hangi pozisyonda kapatılacağı konusunda fikir birliği yoktur. Ancak literatürde ve bu çalışmada görüldüğü gibi fleksiyon pozisyonunda gerçekleştirilen onarımların fonksiyonel sonuçlarının erken dönemde daha iyi olduğu düşüncesindeyiz.

Anahtar kelimeler: Diz replasman artroplastisi; hareket açıklığı; eklem; rehabilitasyon 


\begin{abstract}
Aim: After total knee arthroplasty (TKA), there are publications showing the importance of soft tissue balance in pain control and functional results. In existing publications there is no consensus on which position should be the insicion closed. In this study, we aimed to investigate the effect of the incision closure in the full flexion position or in full extension position during TKA and the effect on postoperative pain and function.
\end{abstract}

Materials and Methods: A total of 61 patients who were scheduled for TKA operation due to severe gonarthrosis were included in the study. Thirty patients who were sutured while the knee was in the maximum flexion position in the incision of the TKA sequence were identified as Group1, and 31 patients sutured in the full extension position were determined as Group 2. Demographic characteristics (age, weight, body mass index (BMI)) of the patients. preop, postoperative 1st week, postoperative 2 nd week motion range and pain scores were compared between the groups.

Results: There was no significant difference between the groups in terms of VAS values in the preoperative period. In the 1 st week postoperative range of motion and pain scores were significantly lower in Group 1 ( $p<0.001$ ). No significant difference was observed between the groups at the 6 th week.

Conclusion: There is no consensus on which position the incision will be closed in TKA. However, in the literature and as seen in the present study, we think that the functional results of the repairs performed in the flexion position are better in the early period.

Key words: knee replacement Arthroplasty; range of motion; articular; rehabilitation

\section{Giriş}

Total diz artroplastisi (TDA) sonrasında ağrı düzeyini ve fonksiyonel sonuçları değiştiren birçok etken mevcuttur. Bunlar arasında kullanılan implantın tipi, cerrahiteknik, cerrahın tecrübesi gibi etkenler sıralanabilir [1-3]. Günümüzde erken ve geç dönemde hastaların ağrı düzeylerini değerlendirmek için ağrı skalaları kullanılmaktadır. Aynı zamanda operasyon sonrasında elde edilen eklem hareket açıklığı (EHA) da fonksiyonel sonuçları doğrudan etkilemektedir. Ağrının fazla olması, EHA'daki kısıtılık, rehabilitasyon ve hastanede kalış süresini uzatabilmekte ve maliyeti arttırmaktadır [4-6].

Ağrı kontrolü ve fonksiyonel sonuçların arttırılmasında yumuşak doku dengesinin önemini gösteren yayınlar mevcuttur. İnsizyon bölgesindeki gerginlik, hematom oluşması aynı zamanda ekstensör mekanizmanın uyumsuz kapatılmasının erken dönemde kötü fonksiyonel sonuçlar doğurabileceği bildirilmiştir [7-14].

Dizin fleksiyon pozisyonundayken insizyonun kapatılmasının daha iyi fonksiyonel sonuçlar doğuracağını bildiren yayınlar olmakla birlikte, hangi pozisyonda kapatılması gerektiği konusunda fikir birliği yoktur.

Bizde bu çalışmada TDA sırasında dizin tam fleksiyon pozisyonunda insizyonun kapatılması ile tam ekstansiyon pozisyonda kapatılmasının, postoperatif ağrı ve fonksiyona olan etkisini araştırmayı amaçladık. Dizin tam fleksiyon pozisyonunda yapılan onarımın fonksiyonel sonuçlarının daha iyi olacağını hipotez ettik.

\section{Gereç ve Yöntemler}

$\mathrm{Bu}$ retrospektif çalışma için Medical Park Silivri Hastanesi başhekimliğinden ocak 2019 tarihinde izin alındı. Medical Park Hastanesi Akademik Kurulu'ndan etik onayı alınarak çalışma yapılmıştır. Bu çalışma Helsinki Illkeler Deklarasyonuna uygun olarak hazırlanmıştır. Tüm hastalardan cerrahi girişim öncesinde yazııı aydınlatılmış onam alınmıştır.Haziran 2017 tarihinden Nisan 2018 tarihine kadar ortopedi polikliniğine diz ağrısı nedeniyle başvuran, ileri derece gonartroz nedeniyle TDA operasyonu planlanan 61 hasta çalışmaya dahil edildi. Nöromusküler hastalık, geçirilmiş septik artrit hikayesi, preoperatif $>20^{\circ}$ varus ya da valgus,$>30^{\circ}$ fleksiyon kontraktürü bilateral aynı seans uygulanan operasyonlar ve revizyon cerrahileri çalışmaya dahil edilmedi. TDA sırasından insizyonu diz maksimum fleksiyon pozisyonundayken sütüre edilen 30 hasta Grup1 olarak, tam ekstansiyon pozisyonunda sütüre edilen 31 hasta Grup 2 olarak belirlendi.

\section{Cerrahi Prosedür}

Tüm hastalar aynı cerrah tarafından spinal anesteziyle turnike hemostazı altında opere edildi. Orta hat insiziyonunu takiben medial parapatellar yaklaşım kullanıldı. Tüm hastalarda çimentolu bağ koruyan genesis II (Smith \& Nephew INC, 
Memphis, TN) protez sistemi kullanıldı. Hiçbir hastada patella yüzey değişimi uygulanmadı, elektrokoter ile desensitizasyon yapıldı.

Grup 1'de insizyon maksimum fleksiyon pozisyonunda, Grup 2'de tam ekstansiyon pozisyonunda kapatıldı. Hastalar opeasyondan cerrahi dren klempli olarak çıkarıldı ve klemp operasyonun 2. Saatinde açıldı. 36 saat serbest drenajda takip edilerek cerrahi dren çekildi çekildi. Takip hemoglobin (hb) değerleri <9gr/dl. olan hastalara allojenik kan transfüzyonu yapıldı. Ağrı kesici protokolü olarak hastalara 8 saatte bir asetaminofen, 12 saatte bir tenoxicam rutin olarak uygulandı. İhtiyaç olması halinde tramadol dozlar arasında 8 saat olacak şekilde uygulandı. Derin ven tromboz proflaksisi için düşük molekül ağırlıklı heparin (Clexane,Sanofi) postoperatif 4 hafta boyunca uygulandı. Hastalar opeasonun 24. Saatinde tam yük verdirilerek yürütüldü ve aktif rom egzersizleri başlandı.

Hastaların ağrı düzeylerinin değerlendirmesi için visual analog scale (VAS) skoru kullanıldı. VAS skoru servis hemşireleri tarafından değerlendirildi. Fonksiyonel değerlendirme için EHA miktarı ölçüldü. EHA ölçümler ameliyatı yapan cerrah tarafından yapıldı.

Gruplar arasında (1) hastaların demografik özellikleri (yaş, kilo,beden kitle indeksi (BKI),) (2) preop, postop 1. hafta, postop 2. hafta EHA değerleri ve VAS skorları karşılaştırıldı. İstatistiki değerlendirmeler SPSS versiyon 13 programı uygulanarak belirlenmiştir. Her parametre için SPSS korelasyon analizleri yapılmış gruplar arası karşılaştırmalar için Mann Whitney U-Testi kullanılmıştır.

\section{Bulgular}

Çalışmaya alınan toplam 61 hastanın demografik özellikleri açısından gruplar arasında anlamlı bir farklılık yoktur (Tablo 1)

\begin{tabular}{|c|c|c|}
\hline & Grup 1 & Grup 2 \\
\hline Yaş & $70,6 \pm 7,5$ & $71,8 \pm 8,1$ \\
\hline \multicolumn{3}{|c|}{ Cinsiyet } \\
\hline Kadın & $18(\% 64,2)$ & $17(58,6)$ \\
\hline Erkek & $10(35,7)$ & $12(41,3)$ \\
\hline BMI & $32,8 \pm 4,2$ & $33,6 \pm 3,3$ \\
\hline \multicolumn{3}{|c|}{ Ameliyat edilen taraf } \\
\hline Sağ & $13(\% 46,4)$ & $12(\% 41,3)$ \\
\hline Sol & $15(\% 53,5)$ & $17(\% 58,6)$ \\
\hline
\end{tabular}

Gruplar arasında yaş, cinsiyet, beden kitle indeksi (BKI) ve ameliyat edilen taraf açısından anlamlı bir fark izlenmemiştir.
(Tablo 2)'de Grup 1 ve Grup 2'ye ait EHA değerleri preop, postoperatif 1 . hafta ve postoperatif 6 . haftada ölçülen değerlerin ortalaması gösterilmiştir. (Tablo 3)'de

\begin{tabular}{|c|c|c|}
\hline & Grup 1 & Grup 2 \\
\hline Preoperatif & $77,5 \pm 3,0$ & $71,8 \pm 8,1$ \\
\hline Postop 1. Hafta & $94,1 \pm 3,4$ & $88,9 \pm 3,5$ \\
\hline Postop 6. Hafta & $117,0 \pm 5,7$ & $115,0 \pm 5,6$ \\
\hline
\end{tabular}

\begin{tabular}{lcc}
\multicolumn{2}{l}{ Tablo 3: VAS değerleri } \\
& Grup 1 & Grup 2 \\
\hline Preoperatif & $7,3 \pm 0,6$ & $7,3 \pm 0,6$ \\
\hline Postop 1. Hafta & $2,7 \pm 0,6$ & $4,6 \pm 0,6$ \\
\hline Postop 6. Hafta & $1,9 \pm 0,7$ & $2,0 \pm 0,7$ \\
\hline \multicolumn{2}{l}{ Tüm sonuçlar ortalama, \pm standart sapma olarak gösterimiştir. }
\end{tabular}

VAS değerleri Grup 1 ve Grup 2 için preop, postoperatif 1. hafta ve postoperatif 6 . hafta için gösterilmiştir.

Gruplar arasında VAS değerleri açısından preoperatif dönemde anlamalı bir fark yoktur. Postop 1. haftada VAS değeri Grup 1'de anlamlı oranda düşüktür $(p<0,001)$. 6. hafta incelendiğinde gruplar arasında yine anlamlı bir fark görülmemektedir. EHA açısından da Preoperatif dönemde ve postoperatif 6 . haftada gruplar arasında anlamlı bir farklılık görülmemektedir. Buna karşılık Postop 1. Hafta da EHA Grup 1'de anlamlı oranda fazladır $(P<0,001)$. Gruplar arası istatistiksel analiz sonuçları (Tablo 4)'te gösterilmiştir. Ameliyat sonrası her iki gruptaki hastalarda da yara yeri ile ilgili komplikasyon izlenmedi.

\begin{tabular}{lll}
\multicolumn{3}{l}{ Tablo 4: Gruplar arası VAS ve EHA değerlerinin karşılaştırılması } \\
\cline { 2 - 2 } & VAS P* & EHA P* \\
Preoperatif & $=0,904$ & $=0,726$ \\
Postop 1. Hafta & $=0,001$ & $=0,001$ \\
Postop 6. Hafta & $=0,594$ & $=0,687$ \\
*P Mann-Whitney U testi &
\end{tabular}

\section{Tartışma}

Çalışmamızın kısıtılıkları retrospektif olması ve hastaların postoperatif kayıtlı verilerinin 6 hafta ile sınırlı olmasıdır.

Çalışmamızda VAS değeri insizyonu tam fleksiyon pozisyonunda kapatılan hastalarda erken postoperatif dönemde [1.Hafta] anlamlı oranda düşüktür. Aynı grupta EHA değerinin de tam fleksiyon da onarım yapılmış hastalarda daha yüksek olduğu görülmüştür. Daha önceki çalışmalarda hastaların erken dönemdeki ağrı düzeyinin az olduğu ve EHA'sı yüksek olan hastaların fonksiyonel sonuçlarının daha iyi olduğu bildirilmiştir [3]. Çalışmamızda insizyonun kapatılma 
pozisyonu incelenmiş olup literatürde erken dönem ağrı ve EHA üzerine implant dizaynının, turnike kullanımının etkilerinin değerlendirildiği çalışmalar mevcuttur [8-11].

Ekstensör mekanizmadaki uygunsuz onarımın kısalma ve gerginlik ile sonuçlandığının bildiren yayınlar mevcuttur [11,15-19]. TDA inzisyonu kapatılırken dizin pozisyonu ekstensör mekanizmanın ideal pozisyonda kapatılması açısından önemli olduğunu düşünmekteyiz.

İnsizyonun fleksiyon posizyonda kapatılmasının fonksiyonel sonuçları daha iyi etkilediğini bildiren yayınlar olduğu gibi ekstensiyon pozisyonunda da onarımın yapılabileceğini bildiren yayınlar vardır $[16,20,21]$. Biz çalışmamızda pozisyonun 1. Haftada anlamlı oranda ağrıyı azalttığı, EHA'yı arttırdığı sonucuna ulaştık. Buna karşılık 6. haftada fonksiyonel sonuçlar arasında anlamlı bir farklılık görülmemiştir. Bunu tam ekstensör mekanizma adaptasyonundaki uygunsuzluğun ameliyatın erken döneminde fonksiyonel sonuçları kötü yönde etkilediği ancak takip eden dönemdeki rehabilitasyon sürecinde tekrar adaptasyonun sağlanabildiği olarak yorumlamaktayız.

King ve arkadaşları [15] çalışmasında insizyonun 120 derece fleksiyonda, Sukur ve arkadaşları, [22] 90 derece fleksiyonda kapatıldığında, ekstensiyon pozisyonuna göre daha iyi sonuçlar alındığını savunmuşlardır. Masri ve arkadaşları [16] 60 derece fleksiyon ile ekstansiyon pozisyonunu karşılaştırıp arada anlamlı bir fark olmadığını savunmuşlardır. Biz çalışmamızda her hastanın ekstensör mekanizma boyunun ve esnekliğinin farklı olduğunu düşünerek dizin maksimum fleksiyon pozisyonundayken onarım gerçekleştirdik. Ekstensör mekanizma diziliminin bu şekilde daha iyi adapte edilebileceği düşüncesindeyiz.

Çalışmamızda tüm hastalar aynı cerrah tarafından, aynı implant sistemi kullanılarak ameliyat edilmiştir. Bunu çalışmamızın üstün yanı olarak değerlendirmekteyiz. Bilindiği gibi implantın tipi ve kullanılan cerrahi teknik fonksiyonel sonuçları yakından etkilemektedir. Bu yönüyle çalışma gruplarımız homojendir.

Sonuç olarak TDA da insizyonun hangi pozisyonda kapatılacağı konusunda fikir birliği yoktur. Ancak literatürde ve bu çalışmada görüldüğü gibi fleksiyon pozisyonunda gerçekleştirilen onarımların fonksiyonel sonuçlarının erken dönemde daha iyi olduğu görülmüştür.

\section{Çıkar Çatışması / Finansal Destek Beyanı}

Çalışmayı maddi olarak destekleyen kişi/kuruluş yoktur ve yazarların herhangi bir çıkar dayalı ilişkisi yoktur.

\section{Kaynaklar}

1. Deng QF, Gu HY, Peng WY, Zhang Q, Huang ZD, Zhang C, Yu YX. Impact of enhanced recovery after surgery on postoperative recovery after joint arthroplasty: results from a systematic review and meta-analysis.Postgrad Med J. 2018; 94: 678-93

2. Salmon P, Hall GM, Peerbhoy D, Shenkin A, Parker C. Recovery from hip and knee arthroplasty: patients' perspective on pain, function, quality of life, and well-being up to 6 months postoperatively. Arch Phys Med Rehabil 82: 360-66

3. Kornuijt A, de Kort GJL, Das D, Lenssen AF, Van der Weegen W. Recovery of knee range of motion after total knee arthroplasty in the first postoperative weeks: poor recovery can be detected early. Musculoskelet Surg 2019; Jan 9.

4. Grosso MJ, Neuwirth AL, Boddapati V, Shah RP, Cooper HJ, Geller JA. decresing length of hospital stay and postoperative complications after primary total hip arthroplasty: a decade analysis from 2006 to 2016. J Arthroplasty 2019; 34: 422-25

5. Mears SC, Edwards PK, Barnes CL. How to decrease length of hospital stay after total knee replacement. J Surg Orthop Adv 2016; 25: 2-7

6. Waimann CA, Fernandez-Mazarambroz RJ, Cantor SB, LopezOlivo MA, Zhanq H, Landon GC, Siff SJ, Suarez-Almazor ME. Costeffectiveness of total knee replacement: a prospective cohort study. Arthritis Care Res 2014; 66: 592-99

7. Schwarzkopf R, Ho J, Quinn JR, Snir N, Mukamel D. Factors influencing discharge destination after total knee arthroplasty: a database analysis. Geriatr Orthop Surg Rehabil 2016;7: 95-99

8. Niki Y, Takeda Y, Harato K, Suda Y. Factors affecting the achievement of Japanese-style deep knee flexion aftertotal knee arthroplasty using posterior-stabilized prosthesis with high-flex knee design. J Orthop Sci 2015; 20:1012-18.

9. Ishida K, Shibanuma N, Matsumoto T, Sasaki H, Takayama K, Toda A et al. Factors affecting intraoperative kinematic patterns and flexion angles in navigated total knee arthroplasty. Knee Surg Sports Traumatol Arthrosc 2015; 23: 1741-47.

10. Sugitani K, Arai Y, Takamiya H, Terauchi R, Nakagawa S, Ueshima $\mathrm{K}$ et al. Factors affecting range of motion after total knee arthroplasty in patients with more than 120 degrees of preoperative flexion angle. Int Orthop 2015; 39: 1535-40.

11. Bade MJ, Kittelson JM, Kohrt WM, Stevens-Lapsley JE. Predicting functional performance and range of motion outcomes after 
total knee arthroplasty. Am J Phys Med Rehabil 2014; 93: 579-85

12. Dennis DA, Heekin RD, Clark CR, Murphy JA, O'Dell TL, Dwyer KA. Effect of implant design on knee flexion. J Arthroplast 2013; 28: 429-38

13. Chiu KY, Ng TP, Tang WM, Yau WM. Review article: knee flexion after total knee arthroplasty. J Orthop Surg 2002; 10:194-202

14. Hoogeboom TJ, van Meeteren NL, Schank K, Kim RH, Miner T, Stevens-Lapsley JE. Risk factors for delayed inpatient functional recovery after total knee arthroplasty. Biomed Res Int 2015: 167643 Epub 2015 Apr 16

15. King TV, Kish G, Eberhart RE, Holzaepfel JL. The 'genuflex' skin closure for total knee arthroplasty. Orthopedics 1992; 15: 1057-58

16. Masri BA, Laskin RS, Windsor RE, Haas SB. Knee closure in total knee replacement: a randomized prospective trial. Clin Orthop Relat Res 1996; 331:81-86

17. Smith TO, Davies L, Hing CB. Wound closure in flexion versus extension following total knee arthroplasty: a systematic review. Acta Orthop Belg 2010; 76: 298-306

18. Motififard $M$, Heidari $M$, Nemati $A$. No difference between wound closure in extension or flexion for range of motion following total knee arthroplasty: a randomized clinical trial. Knee Surg Sports Traumatol Arthrosc 2016; 24:74-78
19. Komurcu E, Yuksel HY, ErsozM, Aktekin CN, Hapa O et al. Effect of surgical closing in total knee arthroplasty at flexion or extension: a prospective, randomized study. Knee Surg Sports Traumatol Arthrosc 2014; 22: 3067-73

20. Emerson RH Jr, Ayers C, Head WC, Higgins. Surgical closing in primary total knee arthroplasties: flexion versus extension. Clin Orthop Relat Res 1996; 331:74-80

21. Cerciello S, Morris BJ, Lustig S, Corona K, Visonà E, Maccauro $G$ et al. The role of wound closure in total knee arthroplasty: $a$ systematic review on knee position. Knee Surg Sports Traumatol Arthrosc. 2016; 24: 3306-12.

22. Şükür E, Öztürkmen Y, Akman YE, Senel A, Azboy İ. The effect of tourniquet and knee position during wound closure after total knee arthroplasty on early recovery of range of motion: a prospective, randomized study. Arch Orthop Trauma Surg 2016;136: 1773-80. 